whereas Listeria monocytogenes is commonly found in the environment and in food. Nevertheless, the aetiology of listeriosis will not be properly understood until we have better information on the incidence, levels of contamination, and conditions for survival and destruction of listeria in a wide variety of foods. With very few exceptions, ${ }^{45}$ sporadic cases of listeriosis have not been linked with the consumption of any particular food. Foods implicated in the outbreaks of listeriosis, such as raw vegetables, ${ }^{6}$ coleslaw, ${ }^{7}$ milk, ${ }^{8}$ and soft cheeses, ${ }^{9}$ have generally been eaten without further heating. Meat paté is the latest, but surely not the last, casualty in the hunt for listeria in food.

Although cook-chill catering has been the subject of concern, adequate reheating of cook-chill meals will substantially, though not completely, ${ }^{10}$ " reduce the risk of consuming micro-organisms that may have multiplied during chill storage. The Department of Health's revised and recently published guidelines on cook-chill and cook-freeze catering systems $^{12}$ include the requirements that $L$ monocytogenes should not be detectable in $25 \mathrm{~g}$ of food at the end of chill storage; that reheating should achieve a core temperature of at least $70^{\circ} \mathrm{C}$ for two minutes; and that the food should be served as soon as possible and in any case within 15 minutes of reheating.

More research into the safety of cook-chill and other modern forms of food provision is urgently needed. The recommendation from the Social Services Committee that the government should review its policy to withdraw funding from agricultural and food research for the "public good" and should contınue to support such research actively even when it falls into the category of "near market" research is to be applauded.' There is, however, an even more pressing need for national case-control studies to address the many unanswered questions in the epidemiology of listeriosis. Such a study was started recently by the Communicable Díseases (Scotland) Unit, and a pilot study by the Communicable Diseases Surveillance Centre is now under way in England and Wales. Until better information is available we lack a sound basis for rational decisions about the control of listeriosis and "listeria hysteria" will continue to flourish.

P J WILKINSON

Director,

Microbiology and Public Health Laboratory,

Derriford Hospital,

Plymouth PL6 8DH

1 House of Commons Social Services Committee. Sixth Report. Food Poisoning: Listeria and Listeriosis. London: HMSO, 1989

Warden J. Listeriosis warning too late. Br.Med f 1989;299:78-9.

3 Department of Health and Social Security, Review of Public Health Laboratory Service. London: DHSS, 1984.

4 Kerr KG, Dealler SF, Lacey RW . Materno-fetal listeriosis from cook-chill and refrigerated food. Lancet 1988;ii: 1133 .

Centres tor Disease Control. Listeriosis associated with consumption of turkey franks $M M W^{\prime} R$ 1989:38:267-8.
.

6 Ho JL, Shand SKN, Frieland G, Eckind P, Fraser DW. An outbreak of type th Listeria monocytogenes infection involving patients from eight Boston hospitals. Arch Intern Med 1986; 146:520-4

Schlech WF, Lavigue PM, Bortolussi RA. Epidemic listeriosis: evidence for transmission by food. N Engl Y Med 1983; 308:203-6

Fleming DW, Cochi SL, MacDonald KL, et al. Pasteurized milk as a vehicle of infection in an outbreak of listeriosis. N Engl F Med 1985;312:404-7.

Linnan MJ, Mascola L, Lou XD, et al. Epidemic Listeriosis associated with Mexican-style cheese. N Eingl f Med 1988;319:823-8.

10 Lund $\mathrm{BM}$, Knox MR, Cole MB. Destruction of Listeria monocytogenes during microwave cooking. Lancet $1989 ; \mathrm{i}: 218$.

11 Sandys GH, Wilkinson PJ. Microbiological evaluation of a hospital delivered meals service using precooked chilled foods $\mathcal{X}$ Hosp Infect 1988;ii:209-19.

12 Department of Health. Chilled and frozen: guidelines on cook-chill and cook-freeze catering systems. London: HMSO, 1989

\title{
The Bamako initiative
}

\section{Financing health in Africa by selling drugs}

To treat a child with pneumonia for $\$ 2.50$ may seem a bargain, but in Mozambique this might be more than a tenth of a family's monthly income. ${ }^{1}$ This is an example of one of the dilemmas facing the United Nations Children's Fund (Unicef) through its proposal to sell drugs at a profit to help fund primary health care in the countries of subSaharan Africa. ${ }^{2}$ The Bamako initiative-so called because it was introduced at a meeting of African health ministers in Bamako, Mali-is poised to start: Unicef will provide free drugs to participating countries for the first few years; the drugs will be sold to patients; and communities will control the finances. The aims are to establish a revolving drug fund to pay for future drug supplies and to use money left over to maintain and improve primary health care services.

The initiative arose in response to the increasing poverty and reducing resources for health care in Africa caused by falling commodity prices and the strain of loan repayments. There is simply not enough money for health. The Bamako initiative is a fresh strategy to finance health services and prevent them collapsing completely. Though new ideas are desperately needed, organisations and staff working in Africa are concerned that selling donated drugs may not be the answer. ${ }^{34}$

Equity is at risk: charging users may reduce utilisation by the poor. Unicef maintains that people are willing to pay, but the real issues are whether they are able to and at what cost to themselves and their families. Although Unicef agrees that provision of free service for "indigents" is necessary, identifying these people presents problems. Discretionary powers are likely to rest with health staff, who will come under strong pressure to provide free services to friends, family, and others to whom they are obliged. The penniless may stay away from fear of being asked for money. Others may wish to avoid the humiliation of being labelled indigent.

The innovative idea of community financing will be difficult to implement. ${ }^{1}$ Rural populations are expected to manage the money collected from drug sales and decide how it will be spent in improving and extending primary health care services. In many countries managerial skills are rare and local supervision poor; administration is thus likely to be chaotic. Misappropriation and mismanagement of funds could easily occur. In a scheme in Ghana fees collected were not even reaching the fund; they were being kept by the doctor. ${ }^{6}$

Whether the initiative can be sustained is also in doubt: Unicef initially proposed large mark ups on the basic cost of the drugs; now partial recovery of the cost is proposed, although how charges will be set is unclear. Revenue will be in local currency and thus will buy few replacement drugs from overseas. What will happen when the free drugs stop? The Bamako initiative could inadvertently result in health service financing being dependent on a continuous supply of drugs from donors. In fact many countries could make substantial savings without charging by introducing an essential drugs policy along the lines advocated by the World Health 
Organisation, establishing a national drugs list, importing generic drugs at low cost, and ensuring proper storage and distribution.

A further objection to the scheme is the almost inevitable deterioration of rational prescribing: paying patients will see it as their right to demand drugs and injections, which may be inappropriate; and health staff will be under pressure to prescribe if their salary depends on drug profits.

Unicef recognises the enormous problems of implementing the policy, yet its solutions and strategies remain vague. Community management of revolving drug funds is dealt with by initial training courses, but there is no commitment to continued support and evaluation locally. Unicef still expects to scale up schemes rapidly in participating countries to nationwide implementation; yet suddenly introducing the initiative with so many changes and little attention to detail is likely to be counterproductive. Unicef has been criticised before for dreaming up global solutions organised from the top down.

Much basic spade work must be done locally to ensure that the scheme is properly understood. Other sources of funding - whether through risk sharing, insurance schemes, or taxation - need to be considered.$^{8}$ Host governments should commit themselves to continued financial and supervisory input and to maintaining control over their own health services. Avenues of communication between participating staff and governments need to be established and maintained to share the experiences of financing schemes. Gradual and sensitive introduction, with careful monitoring of equity, utilisation, and rational drug use from the outset, is essential to prevent failure of this important proposal.

Research Fellow,

PAUL GARNER

Evaluation and Planning Centre for Health Care,

London School of Hygiene and Tropical Medicine,

London WC1E 7HT

1 Kanji N. Charging for drugs in Africa: UNICEF's "Bamako initiative." Health Policy and Planning 1989; : $110-20$.

2 Grant JP. Africa: the Bamako initiative. In: Unicef. The state of the world's children 1989. Oxford: Oxford University Press, 1989:50.

3 Anonymous. The Bamako initiative [Editorial]. Lancet 1988;ii:1177-8.

4 Chabot J. The Bamako initiative. Lancet 1988;ii:1366-7.

5 Unicef. The Bamako initiative. New York: Unicef, 1988. (Mimeograph E/ICEF/1988/P/L40.)

6 Waddington CJ, Enyimayew KA. A price to pay: the impact of user charges in Ashanti-Akim district, Ghana. International fournal of Health Planning and Management 1989;4:17-47.

Wisner B. GOBI versus PHC? Some dangers of selective primary health care. Soc Sci Med 1988;26:963-9.

8 Hoare (i. Policies for financing the health sector. Health Policy and Planning 1987;2:1-16.

\section{Improving the results of treating gastric cancer}

\section{Demands earlier diagnosis and better surgery}

In England and Wales about 10000 people die each year from carcinoma of the stomach, ${ }^{1}$ and at diagnosis only about $1 \%$ of cases are early (carcinoma confined within the submucosa). ${ }^{2}$ The Japanese, motivated by having an incidence of the disease about three times that in Britain, have increased the proportion of cases of the disease that are diagnosed early from $2 \%$ in $1955^{3}$ to $30 \%$ in $1978 .{ }^{+}$By adhering to a set of rules for describing the condition and its stage ${ }^{5}$ they have made possible accurate assessment of results. Their widespread use of extended lymphadenectomy is now well known: in this procedure (known as R2 resection) an extra "tier" of lymph nodes is removed in addition to those close to the stomach that are normally removed in a conventional gastrectomy (known as $\mathrm{R} 1$ resection). The merits of this operation have not yet been proved by a controlled trial, but its use has yielded much valuable information about lymph node metastasis.

Nodes containing tumour are often not enlarged or hard, so that up to three quarters of them are impossible to detect macroscopically. ${ }^{67}$ The tumour is identified only by painstaking dissection of fresh specimens obtained at gastrectomy and careful histological examination by the methods described in the Japanese rules. If this is not done understaging may occur. In Japan lymph node metastases are present in about one in seven of early cases; with increasing invasion by the tumour into and then out of the gastric wall this proportion increases and the prognosis worsens. ${ }^{+}$About a third of patients in whom the serosa has been reached have metastatic tumour in their lymph nodes. ${ }^{+}$When the serosa is penetrated the proportion rises to four fifths, and over a third of the affected nodes are in the second tier (known as N2 nodes) ${ }^{+5}$; this is beyond the reach of the standard resection in Britain. Most patients in Britain present with the serosa already penetrated, and in over $80 \%$ the lymph nodes have been affected. ${ }^{8}$

The results of treatment in Japan have not been equalled elsewhere. Of 5959 new cases of gastric cancer that were assessed after five years in 1978, resections had been per- formed in $4605(77 \%)$ and extended lymphadenectomy in 3673 ( $80 \%$ of resections). The age corrected five year survival after resection was $81 \%$ for patients with lesions confined within the serosa (with or without disease in the lymph nodes) and $30 \%$ for those with more advanced disease. ${ }^{+}$Overall survival after resection was $60 \%$, and the 30 day postoperative mortality was under $2 \%$. $^{+}$These results are challenging when compared with the British age corrected five year survival of $4 \%$. $^{2}$ Survival in Britain was improved to only $17 \%$ by resection, which was possible in only $27 \%$ of cases. ${ }^{2}$

We do not know the relative contributions to the better results of early diagnosis and better surgery; nor do we know whether the Japanese disease behaves in a less aggressive way than the British version. The remarkable improvement in early diagnosis in Japan has gone hand in hand with improved survival. ${ }^{3}$ The main advaitage of extended lymphadenectomy may lie in its use in patients who have disease in only the first tier of lymph nodes (N1 nodes): the five year survival in such patients is $26 \%$ in those who have had the conventional operation and $63 \%$ in those who have had an extended lymphadenectomy. ${ }^{+}$The apparently normal N2 nodes removed by the extended lymphadenectomy may contain micrometastases that are not detectable even by the Japanese methods. The data must be interpreted with caution, however, because histologically detectable disease in the second tier of nodes may have been missed by the conventional resections. But an extended resection in Japan cures a third of patients who have cancer in the second tier of nodes, and a conventional resection is fruitless in such patients. Most of the cures were, however, in patients whose disease had not passed through the serosa. ${ }^{+}$Such patients (serosa negative, N2 positive) are rarely encountered at present in Britain. Data are scanty on the effect of the type of operation on patients with serosal invasion. Four fifths of the Japanese patients in this category had cancer cells only on the surface of the serosa, and a third of this group survived five years. Only $17 \%$ of those with infiltration into surrounding tissue survived five 